\title{
Job Satisfaction amongst Information Technology (IT) Employees in Bangalore City-A Sociological Approach
}

\author{
Nanjamari.K \\ Research Scholars, Department of Sociology, Bangalore University, Bangalore-560 056,
}

\begin{abstract}
A dilemma the majority organizations look is how to maintain skilled workers As information technology has gone from common to established during the last twenty (20) decades, retaining experienced information technology (IT) employees has turn into extra complicated. Consequently, this study focused on investigative job satisfaction among information technology (IT) employees in Bangalore city in Karnataka state. The primary objective of this study is to ascertain the levels of job satisfaction amongst information technology employees at an IT (information technology) and BPO (Business processing outsource) sector. For the purpose of this study is job satisfaction among information technology (IT) employees. The sample group (N $=100$ ) consisted of permanent and contract male and female extending across the following occupational classes: Individual contributor, junior level management, Middle level management, senior level management. The Job Descriptive Index questionnaire (JDI) measures job satisfaction on five job facets, namely, salary, promotions, working condition, co-workers and the work life balance itself. Descriptive statistics were used to analyze the data. A biographical questionnaire and the Job Descriptive Index questionnaire (JDI) were administered to gather the data. This paper reviewed presented literature to get what other researchers have done to make sure that IT employees obtain job satisfaction.
\end{abstract}

Keywords: Occupation class, Job satisfaction, Information technology, Organizations, Job Descriptive Index

\section{Introduction}

It is very clear that the world is flat due to information technology (IT). IT has agitated the world and brought about worldwide industry. However based on the Information Systems Strategy Triangle, a company has to balance its commerce, organizational and information systems strategies to be booming. It is, consequently, not amazing that the job satisfaction of the IT employees is leading to the achievement of any commerce these existence. As the atmosphere of IT continues to rise, the new multifaceted it appears to have become and the new needy the present worldwide neighborhood is to the promise of technological solutions to their troubles. This study thus seeks to summarize and analyze the ways and techniques that organizations could be relevant as they occupy the center competencies and capital they hold in a planned approach for the stipulation of job satisfaction. Using the IT (information technology) and BPO (Business processing outsource) sector area for this study, the reason is to observe how much the formerly mentioned factors distress the job satisfaction of IT employees. Job satisfaction is significant to employees since it can influence their universal strength, cheerfulness and work/life balance. Job satisfaction is of significance to employers because employees who are dissatisfied with their occupation have senior tariff of malingering, are more likely to give up their jobs, get there behind for work, make less than colleagues who are better-off in their jobs and can unenthusiastically change the spirits of the organization. A low altitude of job satisfaction is also reflected in an organization's substructure procession as the costs connected with dissatisfaction employees can willingly be deliberate by looking at what an organization spends hiring and preparation fresh employees, and also found that when low levels of job satisfaction led employees to discover other service, their previous colleagues' job satisfaction levels were exaggerated unenthusiastically suitable to the stress of adjusting to fresh co-workers. This study will center of attention on two aspects of job satisfaction, one extrinsic and one fundamental that have been wellknown in the research that has been done on the job satisfaction factors of information technology employees: their need for independence and their aspiration to precede within their organizations in Bangalore city Karnataka state. (Cropanzano, et al. and Ghazzawi 1990)

\section{Background of the Study}

Job satisfaction, as a general thought, depends on the contract among an individual's totality of attitudes, happiness, behavioral patterns, emotional responses, social roles, and other individual personality that bear over long episode of time and that person's work atmosphere. The work an individual performs goes beyond an income, it shows status and arrogance, and the bottom line is job satisfaction. The further thought is that people who work in information technology fields are fairly different from other people in their approach to occupation; they do work for money, but they often do the same kind of work just for pleasurable. This one 
characteristic may well make the difference between what factors change job satisfaction in other workers and what factors may be more significant, not as much of significant or exceptional to IT workers.

\section{Problem and Purpose of Study}

A dilemma the majority IT and BPO organizations face is how to maintain skillful employees. As information technology has left from common to establish over the past twenty (20) decades, retaining skillful IT employees has become more complex. Organizations are paying their knowledge workers privileged and higher salaries, rising bonuses and vacation time to no benefit. IT workers continue to job skip, and this is estimate companies and other organizations money, time, human capital and productivity. This study is proposed to include to what is acknowledged about what IT workers require in arrange to have job satisfaction and to focus on the IT employees in a specific area of the Bangalore city Karnataka state. The discussion of job satisfaction in the IT atmosphere typically devolves into a recognizable abstain of different issues: the type of work being done, working conditions and the environments in which IT employees are most essential and universal. In other words, the argument of the job satisfaction of IT employees sounds very much the similar as a discussion of what makes any employees more satisfied with his or her profession, but it is possible that, due to the narrow variety of temperaments and individuality character exhibited by IT employees, this particular group of workers may have a different and individual arrange in which they position what factors of job satisfaction are most significant to them. This study therefore seeks to summarize and analyze the ways and techniques that organizations could apply as they employ the core competencies and resources they possess in a strategic approach for the stipulation of job satisfaction.

\section{Review of Literature}

Herzberg (1959) believed workers were more satisfied with their jobs when they experienced certain intrinsic factors including: responsibility granted on the job, real nature of work done, the feeling of success from work performed and their prospective to proceed within the organization. Work, as described by Magnusson (1989), has long occupied a central role in human existence, and, although the role remains central, the nature of that role is constantly evolving. (Dr.Rao Nemani et al, 2011) (Nezaam luddy (2005) postulates that employees experiencing high satisfaction levels contribute to organizational commitment, job involvement, improved physical and mental health, and proved quality of life both on and off the job. Edwin Locke's (1976) classic definition of job satisfaction has been widely cited in the literature. Locke defines job satisfaction as "a pleasurable or positive emotional state resulting from an appraisal of one's job or job experiences” (p. 1300). Similarly, Hackman \& Oldham (1975) provide an implicit definition of job satisfaction as one's affective reactions to his/her job in their Job Characteristics Model. Both definitions are essentially the same, indicating that job satisfaction is one's "emotional reactions" to one's job. (Lim, S. 2008).

\section{Job Satisfaction in the IT Profession}

The entire of the typical job satisfaction factors be relevant to IT employees presently as they do all employees: recompense, reimbursement, flexible hours, the preference to telecommute, having a excellent superior and delightful colleagues employees, having the opportunity to learn and enhance their skills, being acknowledged for their work and having opportunities to press forward within the organization. IT workers, though, tend to focus on different job satisfaction factors than the ones that satisfy other kinds of employees. The ubiquity of IT in current era warrants the sympathetic of job satisfaction in the IT profession as it relates to the employees' level of job satisfaction in relation to productivity in the organization. As the company atmosphere continues to develop at a rapid rate, organization of each type of industry continues to search for fresh ideas and achievable central part competencies and new skills in IT employees. During organize for an organization to take occupied benefit of the skills and knowledge of their IT employees; it must allocate IT employees more suitably, which will construct a better intellect of success and job satisfaction for IT employees.

\section{Working Conditions of It Employees}

Emphasis on the quality of the work environment is also important simply because this is a place where workers spend most of their time outside of home. Long hours are often spent in the working environment by IT employees. The organizations should help employees fight on-the-job-stress which can improve job satisfaction of its workers and thereby reduce turnover. There are still other work situations that are used to determine job satisfaction, and these typically include how a company handles conflict, benefits, fair policies, level of interaction between management and employees, job security, provision and availability of working tools and resources for performing tasks, growth and advancement opportunities in addition to flexibility, vacation, sick leave with pay, paid holidays, volunteer opportunity, comp days, leave of absence, maternity leave, paternity leave, training and development. With all the above mentioned, it is easy to see why one's work situation is seen as the most important determinant of job satisfaction by many researchers. 


\section{Methodology}

The study was undertaken to analyze the job satisfaction amongst information technology (IT) employees in Bangalore city in Karnataka state. Both primary and secondary data have been used to attain the objectives of the study. The macro aspects of the study are based on the published articles and unpublished works on the theme etc. exclusively in the study, books, journals and bulletins are considered to collect date. The primary date was collated by administering the structured questionnaire and interview schedule in an unofficial environment to the IT professions.100 IT employees (1/2) of total employees were chosen randomly out of 200 IT employees in Bangalore city. The study being purely descriptive, on problematical models and tools were used. The simple statistical tools like percentages and averages used to analyze the data.

\section{Objectives of the Study}

The foremost objectives of the present article are to identify the job satisfaction amongst information technology (IT) employees in Bangalore city in Karnataka state.

\section{Job Satisfaction amongst Information Technology (IT) Employees}

The present paper entitled "Job Satisfaction amongst Information Technology (IT) employees in Bangalore city- A Sociological Approach" seeks to investigate empirically into the point out realities pertaining to the working in IT (Information Technology) and BPO (Business Processing Outsource) industries of Bangalore city. In doing so, it focuses on the Job Satisfaction amongst Information Technology (IT) employees, income, age, educational background, nature of working conditions, and social relationship between other colleagues. This would not only facilitate us to describe the job satisfaction of IT professional but also to examine professional and other individuality with deference to the job satisfaction order.

Table No-1.1 Occupational classification of the respondents

\begin{tabular}{|l|c|c|c|c|c|}
\hline \multicolumn{7}{|c|}{ Occupational Classification } \\
\hline $\begin{array}{l}\text { Type of } \\
\text { Industry }\end{array}$ & $\begin{array}{c}\text { Individual } \\
\text { contributor }\end{array}$ & $\begin{array}{c}\text { Junior level } \\
\text { Management }\end{array}$ & $\begin{array}{c}\text { Middle level } \\
\text { management }\end{array}$ & $\begin{array}{c}\text { Senior level } \\
\text { management }\end{array}$ & Total \\
\hline IT & 56 & 08 & 15 & 4 & 83.00 \\
\hline BPO & 05 & 04 & 03 & 05 & 17.00 \\
\hline Total & $\mathbf{6 1}$ & $\mathbf{1 2}$ & $\mathbf{1 8}$ & $\mathbf{0 9}$ & $\mathbf{1 0 0 . 0 0}$ \\
\hline
\end{tabular}

Source: Field Survey 2011

The table No.1.1 shows that the occupational classifications of the sample. The occupational classes of the sample comprises IT employees are working in IT and BPO industries on Individual contributor level of respondents are $(\mathrm{n}=56$ or $56 \%)$, junior level management of the respondents are $(\mathrm{n}=8$ or $8 \%)$ and middle level of respondents $(n=15$ or $15 \%)$, senior level management respondents $(n=4$ or $4 \%)$ professional's occupation. While in BPO ( $\mathrm{n}=5$ or $5 \%)$ of the respondents are Individual contributor, junior level management respondents $(\mathrm{n}=4$ or $4 \%)$, middle level management respondents $(\mathrm{n}=3$ or $3 \%)$, and $(\mathrm{n}=5$ or $5 \%)$ of respondents are senior level management. A total of $1 \%(\mathrm{n}=2)$ did not indicate their occupational category.

\section{Gender and Job Satisfaction}

The distribution is also very similar to the age wise distribution on organizational policy. So we can infer that across sexes and different age groups, the consensus lies with organizational policy towards career development as very encouraging.

Table No-1.2 Gender of the respondents

\begin{tabular}{|l|l|l|l|}
\hline SI. No & \multicolumn{3}{|c|}{ Gender of the respondents } \\
\hline 01 & Male & Female & Percentage \\
\hline 02 & 64 & 36 & 100 \\
\hline Total & $\mathbf{6 4}$ & $\mathbf{3 6}$ & $\mathbf{1 0 0 . 0 0}$ \\
\hline
\end{tabular}

Source: field Survey 2011

The table No.1.2 shows that the presents the gender distribution of the sample. The sample was representative of a larger number of male respondents to that of female respondents. Male respondents comprised of $64 \%(n=64)$ compared to $36 \%(n=36)$ female respondents. The high response rate with regards to the male respondents is attributed to the fact that the large number of males in this division is due to the nature of the work where employees are expected to lift profound boxes on a incessant foundation. 


\section{Age and Job Satisfaction}

Age of the respondents is measured as a significant demographic up-and-down in the present woke. It is understood that age of the respondents may manipulate in ascertaining the profession. The present study, age of the respondents is classified into four groups as 22-29 years, 30-39 years, 40-49 years, and 50 years and older. Data pertaining to age of the respondents are presented in the following table.

Table No 1.3 Age of the respondents

\begin{tabular}{|c|c|c|c|}
\hline SI. No & Particulars (in years) & No. of respondents & Percentage \\
\hline 01 & 22-29 years & 47 & 47.00 \\
\hline 02 & 30-39 years & 30 & 30.00 \\
\hline 03 & 40-49 years & 15 & 15.00 \\
\hline 04 & 50 years and older & 08 & 08.00 \\
\hline \multicolumn{2}{|c|}{ Total } & $\mathbf{1 0 0}$ & $\mathbf{1 0 0 . 0 0}$ \\
\hline
\end{tabular}

Source: Field Survey 2011

The table No.1.2 shows that the age distribution of the sample is presented in table. The majority of the respondents $(n=47$ or $47 \%)$ fall in the age category $22-29$ years. This is followed by $30(30 \%)$ of the respondents in the age category 30-39 years. The age category $40-49$ years old, constitutes $15 \%(n=15)$ of the sample. The minority of the respondents $(\mathrm{n}=08$ or $8 \%)$ fall in the age category of 50 years and older. One $(0.5 \%)$ respondent did not indicate his/her age. From the ensuing results it can therefore be concluded that the majority of the workforce participating in the study is fairly young, ranging between the ages 22-29 years old.

\section{Educational Level and Job Satisfaction}

Education plays a significant role in influential affecting and molding the life of individuals. Due to highly technological and employees environment of the occupation in IT industry it is preferred to hire employees with proper educational qualification. This ensures that the excellence of the work provided is not compromised within a few cases.

Table No-1.4 Educational Background of the respondents

\begin{tabular}{|c|c|c|c|}
\hline SI. No & Educational Background & No. of respondents & Percentage \\
\hline 01 & Graduate & 57 & 57.00 \\
\hline 02 & Under Graduate & 15 & 15.00 \\
\hline 03 & Post Graduate & 28 & 28.00 \\
\hline \multicolumn{2}{|c|}{ Total } & $\mathbf{1 0 0}$ & $\mathbf{1 0 0 . 0 0}$ \\
\hline
\end{tabular}

Source: Field Survey 2011

The table No.1.3 shows that the education level of the sample. The table depicts that the majority of the respondents, $57 \%(\mathrm{n}=57)$ has an educational level of graduates, whilst $15 \%(\mathrm{n}=15)$ possess an educational level of under graduates, and twenty eight respondents $(28 \%)$ has possess a post graduate qualification. One per cent $(0.5 \%)$ of the respondents did not indicate their educational qualification. It can therefore be concluded that the Directorates where the study was conducted mostly employs individuals with an educational level of graduates.

\section{Industry Length of Service and Job Satisfaction}

As the IT industry in India is in its very nascent stage, therefore the existence of high experienced work force is force is nearly negligible. From the year of industry experience of the respondents, an analogy can be drawn with respect to the existence of IT industry in India.

Table No.1.5 Industry Length of service

\begin{tabular}{|c|c|c|c|}
\hline SI. No & Number of years & No. of respondents & Percentage \\
\hline 01 & $<2$ years & 21 & 21.00 \\
\hline 02 & $3-10$ years & 54 & 54.00 \\
\hline 03 & $11-20$ years & 15 & 15.00 \\
\hline 04 & $21-30$ years & 09 & 09.00 \\
\hline 05 & $>30$ years & 01 & 01.00 \\
\hline \multicolumn{2}{|c|}{ Total } & $\mathbf{1 0 0}$ & $\mathbf{1 0 0 . 0 0}$ \\
\hline
\end{tabular}

Source: Field Survey 2011

It can be viewed in table No.1.5 that the majority of the respondents $(n=54$ or $54 \%)$ fall in the $3-10$ years service group and 21 respondents $(21 \%)$ fall in the < 2 years' service group. Fifteen respondents $(15 \%)$ 
fall in the 11-20 years service group while 9 respondents (9\%) fall in the less than 21-30 years service group. The smallest number of respondents $(\mathrm{n}=1$ or $0.5 \%)$ fall in the less than 30 years service group. One $(0.5 \%)$ of the respondents did not indicate their years of service at the organization.

\section{Income: (Individual Income per Month) and Job Satisfaction}

Earning capability plays a significant role in the life of an individual. The IT employees are the very high salaries they earn. Compared to the other in the same occupation and similar age and educational background. It improves living conditions, changes their attitudes, life styles, increasing their self-assurance, gives decision making power and creates awareness etc., the following table show the income of the respondents is as follows.

Table No-1.6 Individual Income (per month) of the respondents

\begin{tabular}{|c|c|c|c|}
\hline SI. No & Individual Income (per month) & No. of respondents & Percentage \\
\hline 01 & Less than 40-50 Thousand & 47 & 47.00 \\
\hline 02 & Rs/ 50-60 Thousand & 36 & 36.00 \\
\hline 03 & Rs/ 60-70 Thousand & 14 & 14.00 \\
\hline 04 & Rs/70 Thousand above & 03 & 03.00 \\
\hline \multicolumn{2}{|c|}{ Total } & $\mathbf{1 0 0}$ & $\mathbf{1 0 0 . 0 0}$ \\
\hline
\end{tabular}

Source: Field Survey 2011

The table No.1.4 shows that the displays suggest that monthly income salary drawn by IT professional's distribution of the sample. The majority of the respondents ( $\mathrm{n}=47$ or $47 \%$ ) earn between Rs 4050 thousand per month. Thirty six respondents (36\%) earn more than Rs 50-60 thousand per month, whilst 14 of the respondents (14\%) earn between Rs 60-70 thousand per month. Only 03 of the respondents (3\%) earn more than Rs 70 thousand above per month. One $(0.5 \%)$ of the respondents did not indicate his/her monthly income.

\section{Marriage Status and Job Satisfaction}

Due to exposure to western and cosmopolitan culture and financial freedom, the social outlook of IT employees towards marital relationship can be reviewed to identity, if their subsist any significant variances from the earlier generation. Individual may suppose to get a change left from habitual norms linked to masculinity and marriage along with IT employees; somewhere there are large numbers of women, working simultaneously very much for long hours and where they expose to western and sophisticated society.

Table No.1.7 Type of marriage

\begin{tabular}{|c|c|c|c|}
\hline SI. No & Type of marriage & No. of respondents & Percentage \\
\hline 01 & Single & 35 & 35.00 \\
\hline 02 & Married & 63 & 63.00 \\
\hline 03 & Divorced & 02 & 02.00 \\
\hline \multicolumn{2}{|c|}{ Total } & $\mathbf{1 0 0}$ & $\mathbf{1 0 0 . 0 0}$ \\
\hline
\end{tabular}

Source: field survey 2011

Since the data in table No 1.5 , shows that type of marriage of the sample the majority of respondents (n $=35$ or $35 \%)$ are single. $(n=63$ or $63 \%)$ of the respondents are married, and only $(n=2$ or $2 \%)$ respondents of them had divorced. Their indicates that married in almost universal in all age groups. Majority of respondents are married in more numbers. Therefore present is not distinguishable difference in expressions of their thought towards marriage.

\section{Span of Career and Job Satisfaction}

Coming to the occupational variables, span of career of the respondents is positively associated with level of job satisfaction. The relationship is statistically significant at 0.01 levels.

Table No.1.8 Span of career and job satisfaction

\begin{tabular}{|c|c|c|c|c|}
\hline \multirow{2}{*}{ Job satisfaction } & \multicolumn{3}{|c|}{ Span of Career } & \multirow{2}{*}{ Total } \\
\cline { 2 - 4 } & Short & Medium & Long & \\
\hline Medium & $28(28)$ & $3(3)$ & $2(2)$ & 33 \\
\hline High & $45(45)$ & $17(17)$ & $5(5)$ & 67 \\
\hline Total & $\mathbf{7 3}(100.00)$ & $\mathbf{2 0}(\mathbf{1 0 0 . 0 0 )}$ & $\mathbf{7 ( 1 0 0 . 0 0 )}$ & $\mathbf{1 0 0 . 0 0}$ \\
\hline
\end{tabular}

Source: field survey 2011 
Analysis of the data on span of career and job satisfaction indicate to define trend that, as one spends more and more time in his/her occupation the level of job satisfaction increases. It could be observed from the data that, about 45 (45) per cent of the respondents with short span of career exhibit low level of job satisfaction, about 17 (17) per cent of the respondents with medium span of career exhibit high level of job satisfaction and about 5(5) per cent of the respondents with long span of career exhibit high level of job satisfaction. This could mean that as one spend more years in the organization.

Work there is an increasing degree of job satisfaction. Increasing acquaintance with occupational field, and realization of its limitations might be attributed to this positive association. In the case of IT organization could make better provision life security insurance so the employees can have a peaceful retired life.

Further, it is significant to note that; thought there is no definite trend. Data on status of occupational service and job satisfaction are significantly associated at 00.05 levels.

\section{Discussion}

The study examines the job satisfaction among information technology (IT) employees in Bangalore city Karnataka state, area as there has not been any research into this theme with this people. The location of the study is also significant as nowhere as well in the state are organizations more dependent upon knowledge employees than in Bangalore city Karnataka state, and nowhere is the job satisfaction level of knowledge workers more important. Thousands of studies have investigated job satisfaction in general, but the difference in this study is that it takes the factors that affect job satisfaction for all workers and narrow down those factors to the ones studies have shown to be most important to the job satisfaction among information technology (IT) employees. The results of the study could provide a baseline for succeeding studies in other Bangalore cities and towns, which may, eventually, indicate that the job satisfaction of IT employees is influenced by the city in which they live, giving insight into less obvious, but important, basic factors perhaps exclusive to IT workers. The results of the study were presented in tables. The results of this study indicate that general satisfaction is significantly associated with satisfaction levels about independence and fundamental factors.

\section{Conclusion}

This study examined job satisfaction among Information Technology (IT) employees in Bangalore city Karnataka state, neighborhood. The purpose of this study is to quantify the job satisfaction level of IT workers in the Bangalore city, area, paying particular attention to two of the most important factors of job satisfaction for IT workers: self-rule and the occasion for progress. It is, consequently, suggested that future research with a larger sample is essential in order to measure the purpose of these findings to the general population of the IT employees. A further suggestion for future research would be to carry out the survey using a shorter questionnaire to keep away from high numbers of deserted surveys. But perhaps the survey delivery platform company could be persuaded to allow participants to return to the study more than once, giving people the opportunity to answer a few questions per trip so that it's more convenient for them. Future research should compare results of job satisfaction among information technology (IT) employees in the organized sector with the job satisfaction of those in the unorganized sector. Presently, the researcher is oblivious of any other survey of job satisfaction of IT workers having been done on those in the Bangalore city area, thus this study plays a major part in adding knowledge to the IT employees' database.

\section{References}

[1]. Cropanzano, R., Howes, J.C., Grandey, A.A., \& Toth, P. (1997). "The relationship of organizational politics and support to work behaviors, attitudes and stress". Journal of Organization Behavior, 18(2), 159-180.

[2]. Ghazzawi, I. (2008) Job satisfaction among information technology professionals in the US: An empirical study. Journal of American Academy of Business, 13(1), 1-15.

[3]. Dr.Rao Nemani et al, (2011) "Job Satisfaction: Key Factors Influencing Information Technology (IT) Professionals in Washington DC” Int. J. Comp. Tech. Appl., Vol 2 (4), 827-838

[4]. Nezaam luddy (2005) "job satisfaction amongst employees at a public health institution" in the western cape Department of Industrial Psychology, Faculty of Economic and Management Science, University of the Western Cape

[5]. Lim, S. (2008). “Job Satisfaction of Information Technology Workers in Academic Libraries" Library \& Information Science Research. 30(2), 115-121.

[6]. Dore, T. L. (2004). "The relationships between job characteristics, job satisfaction, and turnover intention among software developers". (Doctoral dissertation, Argosy University/Orange County, 2004). Dissertation Abstracts International. 66 (01), 65A. (UMI No. 3162119)

[7]. Fletcher C, \& Williams R. (1996). Performance management, job satisfaction and organizational commitment. British Journal of Management, 7(2), 169-179.

[8]. Gavin, J.H., \& Mason, R.O. (2004). The virtuous organization: The value of happiness in the workplace. Organization Dynamics, 33(4), 379-392. 